\title{
A Case of Biliary Ascariasis in Korea
}

\author{
Jun-Ho Choi', Min Seo ${ }^{2, *}$ \\ 'Division of Gastroenterology, Department of Internal Medicine, Dankook University College of Medicine, Dankook University Hospital, Cheonan \\ 31116, Korea; ' Department of Parasitology and Research Center for Mummy, College of Medicine, Dankook University, Cheonan 31116, Korea
}

\begin{abstract}
Biliary ascariasis is still the leading cause of surgical complication of ascariasis, though its incidence has been dramatically reduced. Herein, we report a case of biliary ascariasis for the purpose of enhancing awareness of parasitic infections as a possible cause. A 72-year-old male visited the emergency room of Dankook University Hospital on 12 July 2015, complaining of right-upper-quadrant pain. By endoscopic retrograde cholangiopancreatography (ERCP), a tubular filling defect in the right hepatic duct was detected. The defect was endoscopically removed and diagnosed as an adult female of Ascaris lumbricoides worm, of $30 \mathrm{~cm}$ length. Upon removal of the worm, the pain subsided, and the patient was discharged without any complication. When treating cases of biliary colic, physicians should not neglect biliary ascariasis as the possible cause.
\end{abstract}

Key words: Ascaris lumbricoides, biliary ascariasis, RUQ pain, ERCP

\section{INTRODUCTION}

Among the surgical complications of ascariasis, biliary migration of adult worms is the most common [1]. Although the natural habitat of Ascaris lumbricoides is usually in the jejunum, they can migrate to the biliary tract, causing biliary colic, obstructive jaundice, and cholelithiasis [2]. Between 1955 and 1989 in Korea, there were 1,198 reported cases of biliary ascariasis, which accounted for $92.2 \%$ of the overall surgical ascariasis patients [3]. Since that time, the incidences of ascariasis have been dramatically reduced; in fact, other than 2 cases in 2001 [4], there has been none reported. We report herein a case of biliary ascariasis for the purpose of enhancing awareness of parasitic infections as a possible cause.

\section{CASE RECORD}

A 72-year-old male visited the emergency room of Dankook University Hospital on 12 July 2015, complaining of right upper quadrant pain. The pain began 15 days before the visit and had worsened by the day of admission. Interestingly, he had been suffering from recurrent hepatobiliary stones for a very

\footnotetext{
- Received 5 October 2017, revised 24 October 2017, accepted 21 November 2017.

*Corresponding author (bbbenji@naver.com)

(C) 2017, Korean Society for Parasitology and Tropical Medicine

This is an Open Access article distributed under the terms of the Creative Commons Attribution Non-Commercial License (http://creativecommons.org/licenses/by-nc/4.0) which permits unrestricted non-commercial use, distribution, and reproduction in any medium, provided the original work is properly cited.
}

long time, and should have undergone cholecystectomy and left hepatectomy 30 and 20 years before, respectively. Additionally, he had been treated for cholangitis due to a common bile duct (CBD) stone and sludge in 2014. On physical examination, no abnormal findings were observed, and the laboratory results were unremarkable except for mild elevation of aspartate aminotransferase, alanine aminotransferase, and gamma-glutamyl transferase $(82 \mathrm{U} / \mathrm{L}, 114 \mathrm{U} / \mathrm{L}, 79 \mathrm{IU} / \mathrm{L}$, respectively; normal range 0-40 U/L, 0-40 U/L, 8-61 IU/L, respectively). Total bilirubin and alkaline phosphatase were within normal limit $(0.98 \mathrm{mg} / \mathrm{dl}$ and $86 \mathrm{IU} / \mathrm{L}$, respectively; normal range 0.2 $1 \mathrm{mg} / \mathrm{dl}, 40-129 \mathrm{IU} / \mathrm{L})$. Cholangitis due to intrahepatic stone was suspected, and accordingly, the patient was referred for endoscopic retrograde cholangiopancreatography (ERCP). A tubular filling defect was detected in the right hepatic duct (Fig. $1 \mathrm{~A})$, and was proved to be a parasite by intraductal sonography. The parasite was endoscopically removed through the ampulla of Vater using the balloon sweeping method, and subsequently was diagnosed as an adult female of A. lumbricoides worm, of $30 \mathrm{~cm}$ length (Fig. 1B). After removal of the worm, the patient's pain subsided. The patient thereupon was treated with albendazole, and discharged without any complication.

\section{DISCUSSION}

Although many hypotheses have been formed to explain the migration of A. lumbricoides to various organs, an impor- 

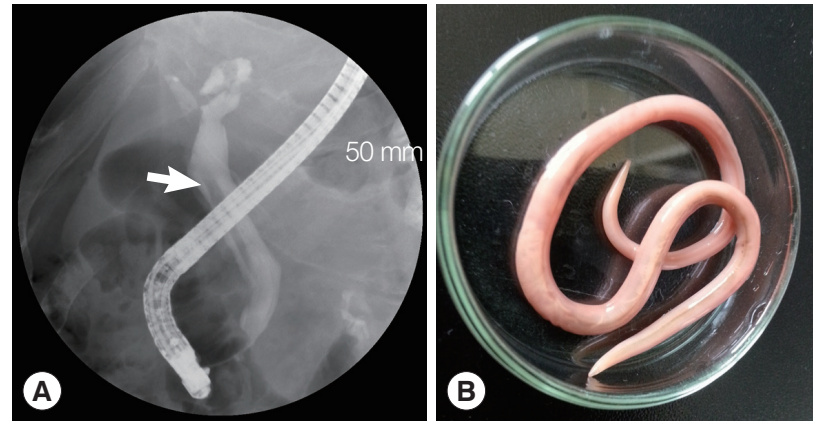

Fig. 1. (A) An endoscopic retrograde cholangiopancreatogram (ERCP) showing a linear filling defect (arrow) in the right intrahepatic duct. (B) The removed worm of Ascaris lumbricoides, 30 $\mathrm{cm}$ in length.

tant pre-requisite for their reaching the biliary tract seems to be a heavy infection [5]. In fact, these days, biliary ascariasis is seen more commonly in endemic countries [5]. In this respect, the recent discovery of biliary ascariasis in Korea seems exceptional. Therefore, even in Korea and other non-endemic countries, the possibility of ascariasis in cases of biliary colic should not be ruled out.

Another interesting finding in the current case was the repetitive formation of hepatobiliary stones. Although it has been suggested that hepatolithiasis can result from the presence of bacteria such as Klebsiella, Escherichia coli, and others, or from a carbohydrate-rich diet, parasitic infection should also be considered an important causative factor [6]. It is for this reason that, in East Asia, where A. lumbricoides and Clonorchis sinensis are prevalent, hepatolithiasis is endemic of 30$50 \%$ prevalence [7]. Notwithstanding, it would be hasty, of course, to assume an association between the frequent recurrence of hepatolithiasis in the patient and his parasitic infection.

In cases of suspicion of biliary ascariasis, ultrasonography (US) has been the imaging modality of choice; however, without careful examination, the diagnosis often is missed [8]. ERCP, alternatively, is a very useful tool, that effectively reveals the characteristic tubular filling defect within the biliary duct. Recently though, invasive ERCP has been replaced by magnetic resonance (MR) cholangiography as the preferred diagnostic procedure for biliary ascariasis [4]. By means of MR cholangiography repeated at $30 \mathrm{sec}$ intervals, movement of live worms within the bile duct can be detected. This technique should be widely employed in the diagnosis of biliary diseases, especially parasite lodgment.
Although the rate of incidence of ascariasis has been dramatically reduced in Korea in recent decades, the estimated number of patients harboring A. lumbricoides was 15,754 in 2012; moreover, approximately 500,000 individuals from highrisk undeveloped countries have immigrated $[9,10]$. When physicians are presented with cases of biliary colic, therefore, biliary ascariasis should not be neglected as a possible cause.

\section{ACKNOWLEDGMENT}

This work was supported by a research fund of Dankook University in 2016.

\section{CONFLICT OF INTEREST}

We have no conflict of interest related to this work.

\section{REFERENCES}

1. Maki T. Surgical diseases due to Ascaris lumbricoides. Progr Med Parasitol Japan 1971; 4: 221-270.

2. Sundriyal D, Bansal S, Kumar N, Sharma N. Biliary ascariasis: radiological clue to diagnosis. Oxf Med Case Reports 2015; 3: 246247.

3. Chai JY, Cho SY, Lee SH, Seo BS. Reduction in the incidence of biliary and other surgical complications of ascariasis according to the decrease of its national egg prevalence in Korea. Korean J Parasitol 1991; 29: 101-111.

4. Hwang CM, Kim TK, Ha HK, Kim PN, Lee MG. Biliary ascariasis: MR cholangiography findings in two cases. Korean J Radiol 2001; 2: 175-178.

5. Das AK. Hepatic and biliary ascariasis. J Glob Infect Dis 2014; 6: 65-72.

6. Dey B, Kausahl G, Jacob SE, Barwad A, Pttakkat B. Pathogenesis and management of hepatolithiasis: a report of two cases. J Clin Diagn Res 2016; 10: 11-13.

7. Feng XB, Zheng SG, Xia F, Ma KS, Wang SG, Bie P, Dong JH. Classification and management of hepatolithiasis: a high volume, single centre's experience. Intractable Rare Dis Res 2012; 1: 151-156.

8. Aslam M, Doré SP, Verbanck JJ, De Soete CJ, Ghillebert GG. Ultrasonographic diagnosis of hepatobiliary ascariasis. J Ultrasound Med 1993; 12: 573-576.

9. Korea Association of Health Promotion. Prevalence of intestinal parasitic infections in Korea - the 8th report -2012. Art Motion, Seoul, Korea. 2012.

10. Korea Employment Information Service. Brief on Employment Trend. Vol. 11. Seoul, Korea. 2013, pp 1-35. 